\title{
Sosialisasi Standar dan Prosedur Keselamatan Pelayaran Wilayah Gugus Kepulauan Sangkarrang Kota Makassar
}

\author{
Andi Sitti Chairunnisa ${ }^{1 *}$, Misliah Idrus ${ }^{1}$, Mansyur Hasbullah ${ }^{1}$, Suandar Baso ${ }^{1}$, Abd. Haris \\ Djalante $^{1}$, Wihdat Djafar ${ }^{1}$, Andi Mursid Nugraha ${ }^{1}$, Andi Dian Eka Anggriani ${ }^{1}$ \\ Departemen Teknik Perkapalan, Fakultas Teknik UNHAS ${ }^{1}$ \\ andi.chairunnisa@yahoo.co.id ${ }^{1 *}$
}

\begin{abstract}
Abstrak
Jaminan keselamatan penumpang dan barang pada pelayaran lokal antar pulau khususnya gugus kepulauan Sangkarrang Kota Makassar masih sangat rendah. Hal ini terlihat dari kondisi pemuatan yang kadang-kadang tidak mempertimbangkan kapasitas muat, posisi penumpang, muatan barang, kelengkapan peralatan keselamatan pelayaran masih sangat minim jumlahnya, kondisi dermaga yang sangat memprihatinkan, serta kondisi teknis kapal yang sudah tidak layak untuk berlayar.

Pemerintah telah mengeluarkan peraturan tentang keselamatan pelayaran rakyat agar secara teknis dapat melindungi kegiatan operasional kapal tersebut, salah satunya adalah persyaratan kelaiklautan kapal tradisonal pengangkut penumpang telah diatur dalam Peraturan Direktur Jenderal Perhubungan Laut Nomor HK.103/2/8/DJPL-17 tanggal 18 April 2017.

Dari hasil sosialisasi yang di laksanakan, diharapkan para pengguna jasa serta pihak operator akan memiliki tingkat kesadaran yang tinggi akan pentingnya keselamatan pelayaran. Luaran dari kegiatan ini adalah meningkatnya kesadaran masyarakat, khususnya masyarakat pengguna jasa dan pemilik armada angkutan laut yang tinggal di wilayah gugus kepulauan Sangkarrang Kota Makassar. Dengan adanya pengabdian ini, akan semakin tinggi kesadarannya tentang pentingnya keselamatan dalam pelayaran, sehingga dalam pelayaran para operator sudah mempersiapkan peralatan keselamatan minimal berupa lifejacket, pelampung dan alat pemadam kebakaran dalam pelayaran. Selain itu pengguna jasa dan pemilik kapal dapat mempertimbangkan kondisikondisi berbahaya yang dapat menyebabkan resiko dalam pelayaran.
\end{abstract}

Kata Kunci: Sosialisasi; Keselamatan; Pelayaran; Gugus; Kepulauan.

\begin{abstract}
The safety guarantee for passengers and goods on local inter-island shipping has been overlooked, particularly in the Sangkarrang island group, Makassar City. The following conditions can be seen: the loading process that neglected ship capacity, the position of passengers and goods, fewer safety equipment pieces, the poor state of the pier, and ship worthiness.

The government has issued a regulation on traditional shipping safety to protect ship operation activities, such as the requirement of conventional passenger ships, which is regulated the Regulation of the Director-General of Sea Transportation Number HK.103 / 2/8 / DJPL-17 dated 18 April 2017.

The program socialization is expected to give awareness of shipping safety for users and operators. This activity's output is the increasing awareness of the community, especially service users and owners of sea transportation fleets who live in the Sangkarrang archipelago, Makassar City. Through this service community program, there will be a higher awareness of the importance of shipping safety. Hence, the operators must prepare minimal safety equipment such as life jackets, buoys, and fire extinguishers on the ship. Besides, service users and ship owners can consider the risk of shipping circumstances.
\end{abstract}

Keywords: Socialization; Safety; Shipping; Group; Islands.

\section{Pendahuluan}

Wilayah kepulauan yang terdapat di Kota Makassar tergabung dalam satu kecamatan yaitu Kecamatan Kepulauan Sangkarrang merupakan kecamatan termuda yang terbentuk tahun 2017. Kecamatan Kepulauan Sangkarrang terletak dibagian utara yang merupakan satu dari lima belas Kecamatan yang terdapat dalam wilayah administrasi Kota Makassar (Gambar 1). 


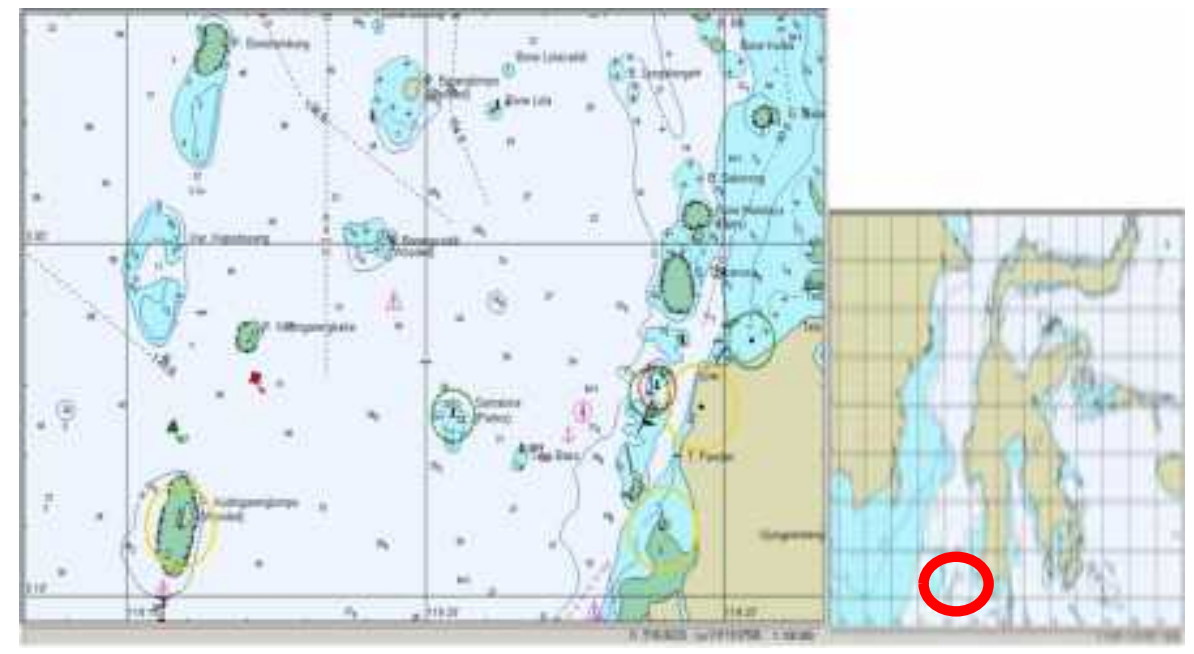

Gambar 1. Wilayah Kecamatan Kepulauan Sangkarrang Kota Makassar

Transportasi yang melayani pergerakan masyarakat dari wilayah gugus pulau ke Kota Makassar terselenggara secara reguler dengan tujuan Dermaga Kayu Bangkoa dan Pelabuhan Paotere. Trayek regular yang ada hanya melayani Pulau Barrang Lompo, Pulau Barrang Caddi dan Pulau Kodingareng Lompo.

Berdasarkan hasil pengamatan di lapangan, jaminan keselamatan penumpang dan barang untuk pelayaran lokal antar pulau khususnya gugus kepulauan Sangkarrang Kota Makassar masih sangat rendah. Hal ini terlihat dari kondisi pemuatan yang kadang-kadang tidak mempertimbangkan kapasitas muat, posisi penumpang, muatan barang, kelengkapan peralatan keselamatan pelayaran masih sangat minim jumlahnya, kondisi dermaga yang sangat memprihatinkan, serta kondisi teknis kapal yang sudah tidak layak untuk berlayar (Gambar 2).
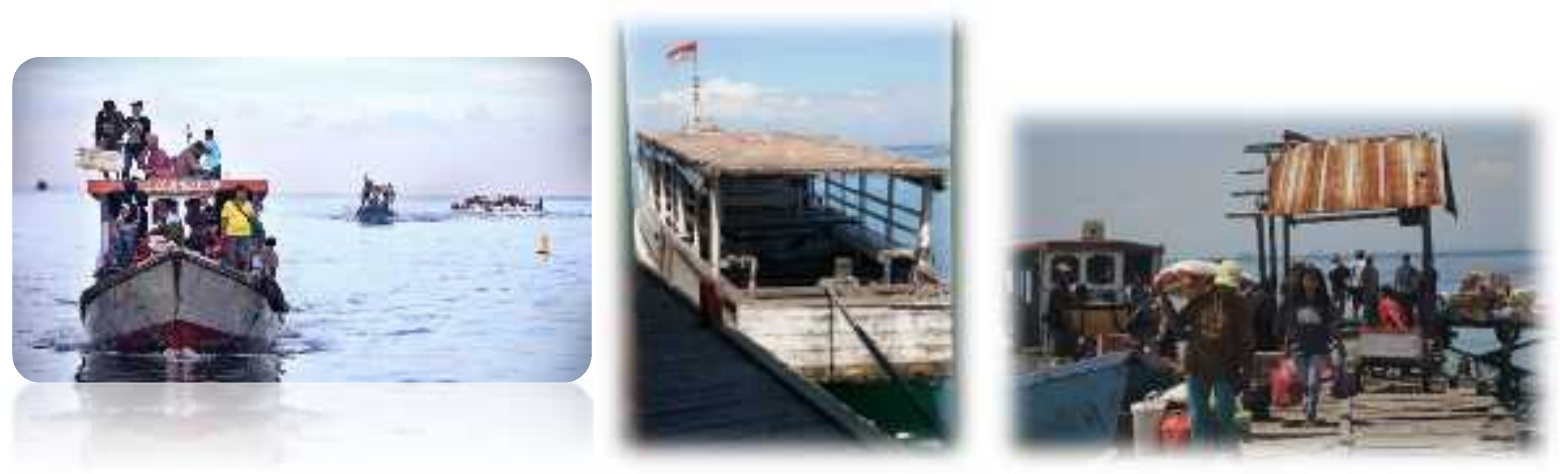

Gambar 2. Kondisi Pemuatan, kondisi dermaga dan kondisi armada angkutan Kepulauan Sangkarrang

Jaminan keselamatan dalam pelayaran di wilayah gugus kepulauan sangat dibutuhkan oleh masyarakat pengguna jasa angkutan laut. Keselamatan pelayaran dapat dijamin apabila kapal yang berlayar dalam kondisi laik laut artinya kapal harus mampu menghadapi berbagai kasus atau kejadian alam secara wajar dalam dunia pelayaran. Selain itu kapal layak menerima muatan dan mengangkutnya serta melindungi keselamatan muatan dan anak buah kapal $(\mathrm{ABK})$. 
Pemerintah telah mengeluarkan peraturan tentang keselamatan pelayaran rakyat agar secara teknis dapat melindungi kegiatan operasional kapal tersebut, salah satunya adalah persyaratan kelaiklautan kapal tradisonal pengangkut penumpang telah diatur dalam Peraturan Direktur Jenderal Perhubungan Laut Nomor (2017). Selain itu Kementerian Perhubungan juga telah menerbitkan Permen RI_A, (2015) tentang Standar Keselamatan dan Permen RI_B, (2015) tentang Standar Pelayanan Penumpang Angkutan Laut. Namun implementasi di lapangan belum sepenuhnya dipraktekkan sehingga dipandang perlu untuk melakukan sosialisasi bagi pemilik armada dan pengguna jasa angkutan laut.

Berdasarkan latar belakang di atas, maka program pengabdian masyarakat dengan topik: Sosialisasi Standar dan Prosedur Keselamatan Pelayaran Wilayah Gugus Kepulauan ini mempunyai tujuan utama yaitu:

1) Memberikan dasar pengetahuan standar dan prosedur keselamatan pelayaran sehingga operator kapal dan pengguna jasa sadar akan pentingnya jaminan keselamatan pada saat berlayar

2) Memberikan pengenalan mengenai perangkat keselamatan standar yang harus terdapat di kapal bagi pemilik kapal dan pengguna jasa transportasi laut wilayah Kepulauan Sangkarrang.

\section{Latar Belakang Teori}

\subsection{Peraturan Keselamatan Pelayaran}

Keselamatan Pelayaran adalah suatu keadaan terpenuhinya persyaratan keselamatan dan keamanan yang menyangkut angkutan di perairan dan kepelabuhanan. Terdapat banyak penyebab kecelakaan kapal laut diantaranya pada persoalan penempatan barang yang tidak memperhitungkan titik berat kapal dan gaya lengan stabil. Untuk angkutan pelayaran rakyat penyebab kecelakaan kapal Sebagian besar karena kelebihan muatan dan kondisi kapal yang sudah tidak layak sacera teknis.

\subsubsection{Manajemen Keselamatan}

Peraturan internasional tentang keselamatan kapal niaga terdapat dalam Konvensi Solas. SOLAS versi pertama diadopsi pada tahun 1914, sebagai respons terhadap bencana yang dialami oleh Kapal Penumpang "Titanic", kedua pada tahun 1929, ketiga pada tahun 1948 dan keempat pada tahun 1960 (kemudian dikenal sebagai SOLAS Convention 1960), diadopsi pada 17 Juni 1960 dan mulai berlaku (entered into force) pada 26 Mei 1965. Ini merupakan tugas utama IMO setelah terbentuknya organisasi tersebut dan merupakan representasi dari langkah maju dalam modernisasi peraturan maritim dan sejalan dengan perkembangan teknologi industri perkapalan.

Pemerintah telah mengadopsi peraturan yang dikeluarkan oleh IMO yakni peraturan tentang International Safety Management Code (ISM-Code) dan mulai diberlakukan sejak tanggal 1 juli 1998 (ISM, 2002). Sistem manajemen keselamatan (ISM-Code) wajib diaplikasikan secara "mandatory" oleh negara-negara yang telah meratifikasi SOLAS. Penerapannya di Indonesia diwujudkan melalui Keputusan Direktur Jenderal Perhubungan Laut Nomor (1996). Berdasarkan hal tersebut, ISM-Code menghendaki adanya komitmen dari manajemen puncak (top management) sampai pelaksana, di darat dan di kapal. ISM-Code dapat dipahami sebagai "Koda Manajemen Keselamatan Internasional untuk Pengoperasian Kapal dengan Selamat dan Pencegahan Pencemaran". 
ISM-Code menetapkan standar untuk membuat pelayaran yang aman dan bahaya yang sekecil mungkin terhadap lingkungan. Selanjutnya manajemen standar termasuk tanggung jawab awak, skenario pelaksanaan tindakan tanggap darurat dapat ditemukan di sini. Ketentuan ini bukan merupakan jaminan tidak terjadinya kecelakaan laut, melainkan dapat membantu memperkecil atau mengurangi kecelakaan dan pencemaran laut dengan menerapkan ketentuan tentang manajemen keselamatan pengoperasian kapal dan pencegahan polusi di laut (Ashury, 2020). Oleh karena itu, ISM code merupakan kewajiban bagi setiap perusahaan, akan tetapi penerapannya yang tepat adalah merupakan tanggung jawab pemilik kapal.

\subsubsection{Regulasi Keselamatan Pelayaran}

IMO telah memberikan arahan tentang pengaturan keselamatan dan keamanan angkutan laut, pencegahan polusi serta persyaratan, pelatihan dan pendidikan awak kapal serta mewajibkan para negara anggota untuk menerapkannya. Negara anggota IMO (flag state) memiliki tanggung jawab untuk melakukan berbagai konvensi internasional bagi kapal-kapal yang mengibarkan bendera negaranya. Namun hingga saat ini kondisi kapal-kapal berbendera Indonesia masih banyak yang belum mampu memenuhi ketentuan IMO, bahkan tidak jarang seringnya terjadi pelanggaran regulasi. Prinsip dasar keselamatan pelayaran menyatakan bahwa kapal yang hendak berlayar harus berada dalam kondisi laik laut (seaworthiness). Artinya, kapal harus mampu menghadapi berbagai kasus atau kejadian alam secara wajar dalam dunia pelayaran. Selain itu kapal layak menerima muatan dan mengangkutnya serta melindungi keselamatan muatan dan anak buah kapal (ABK) (IMO, 1999).

Pemerintah telah mengeluarkan peraturan tentang keselamatan pelayaran rakyat agar secara teknis dapat melindungi kegiatan operasional kapal tersebut melalui Keputusan Dirjen Perhubungan Laut Nomor: PY.66/1/2-02 dimana sebelumnya hanya sampai GT 300 kini dapat ditingkatkan menjadi GT 500. Demikian halnya, pesawat penggerak bantu (mesin) yang sebelumnya dibatasi sampai 150 TK kini dapat ditingkatkan menjadi 535 TK. Peningkatan ukuran dan besarnya tenaga mesin yang digunakan perlu dibarengi dengan kemampuan dan keterampilan awak kapal menyangkut kualifikasi ijazah yang harus dimiliki bagi nakhoda atau perwira kapal lainnya. Untuk mengantisipasi peningkatan tersebut, kemudian dikeluarkan Peraturan Kepala Badan Diklat Perhubungan, (2010) terkait Standar Pelatihan Dasar Keselamatan (BST) Khusus Awak Kapal dan Pekerja pada Kapal Layar Motor (KLM) dan kapal ikan dalam negeri.

\subsubsection{Regulasi / Hukum Pelayaran}

Pelayaran rakyat merupakan salah satu potensi yang amat penting dalam sistem transportasi laut sebagaimana yang terdapat dalam Undang-undang Nomor 17 Tahun 2008. Pelayaran rakyat merupakan kelompok usaha yang dijalankan oleh golongan masyarakat namun kehidupan mereka tampaknya belum memperlihatkan perubahan yang signifikan meskipun telah banyak upaya dilakukan untuk meningkatkan kesejahteraan rakyat.

Peran pelayaran rakyat semakin mengecil setelah sebagian besar transportasi laut diambil alih oleh kapal-kapal niaga bermesin, akan tetapi peran pelayaran rakyat masih tetap diperlukan terutama untuk transportasi antar pulau, daerah terpencil/perbatasan yang sulit dijangkau oleh kapal-kapal konvensional. Demikian pentingnya kapal pelayaran rakyat dalam menggerakkan perekonomian, maka harus dapat dioperasikan dengan selamat, aman, lancar, nyaman, teratur dan efisien dengan biaya yang terjangkau. 


\section{Metode Kegiatan}

Pelaksanaan sosialisasi standar dan prosedur keselamatan pelayaran wilayah gugus kepulauan dilakukan dengan tahapan sebagai berikut:

1. Tahap Persiapan; tahapan ini meliputi pembuatan brosur/leaflet yang memuat informasi mengenai kondisi-kondisi yang yang dapat berbahaya dalam pelayaran, peraturanperaturan yang mengatur tentang keselamatan pelayaran, alat-alat keselamatan standar yang harus terdapat di kapal, serta resiko-resiko yang dapat terjadi jika tidak terdapat jaminan keselamatan selama berlayar. Serta pembuatan stiker keselamatan pelayaran yang bertuliskan "keselamatan pelayaran tanggung jawab kita Bersama". Terdapat 200 brosur dan 200 stiker yang dicetak dan dibagiakan saat sosialisasi (Gambar 3 dan Gambar 4).

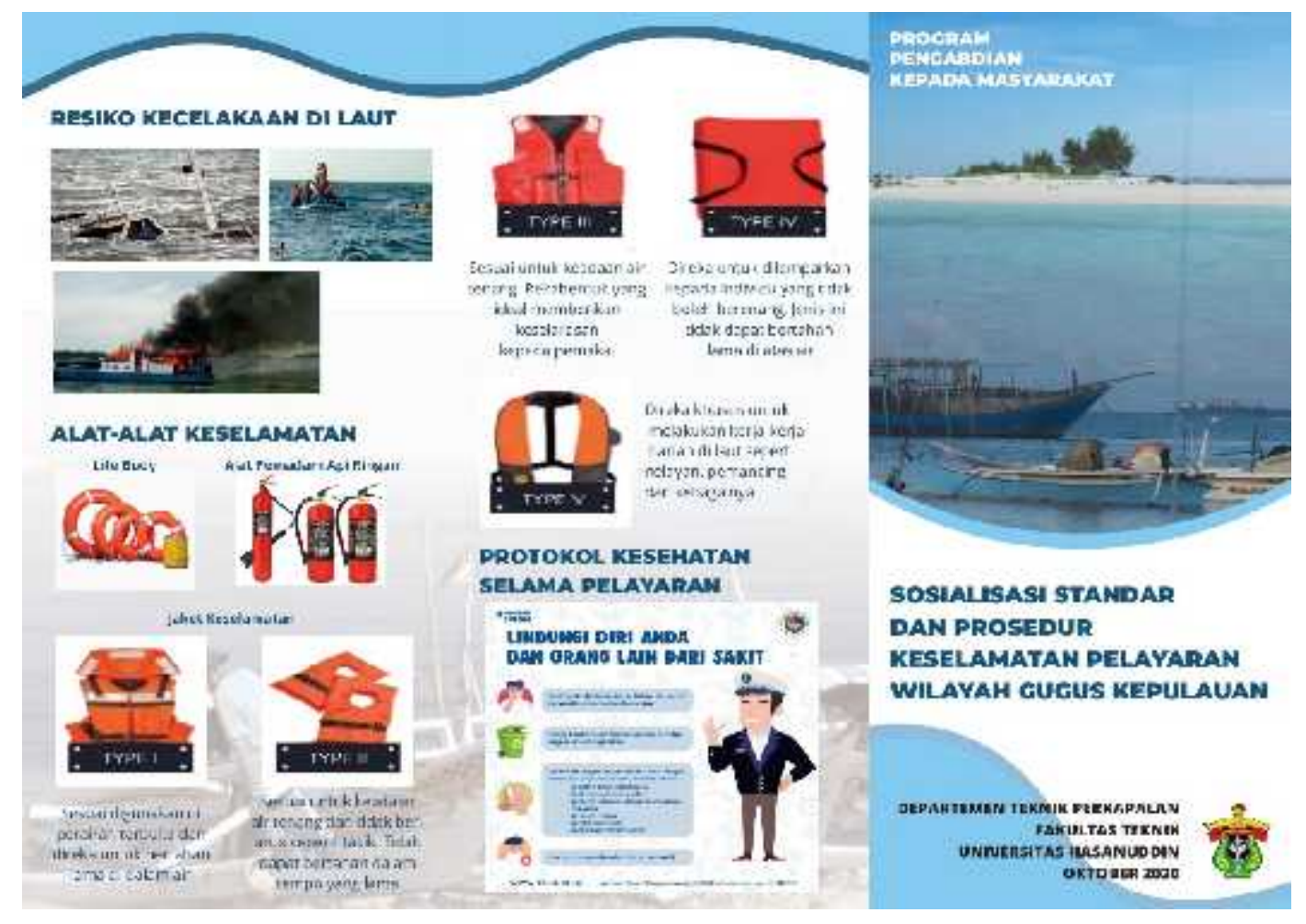




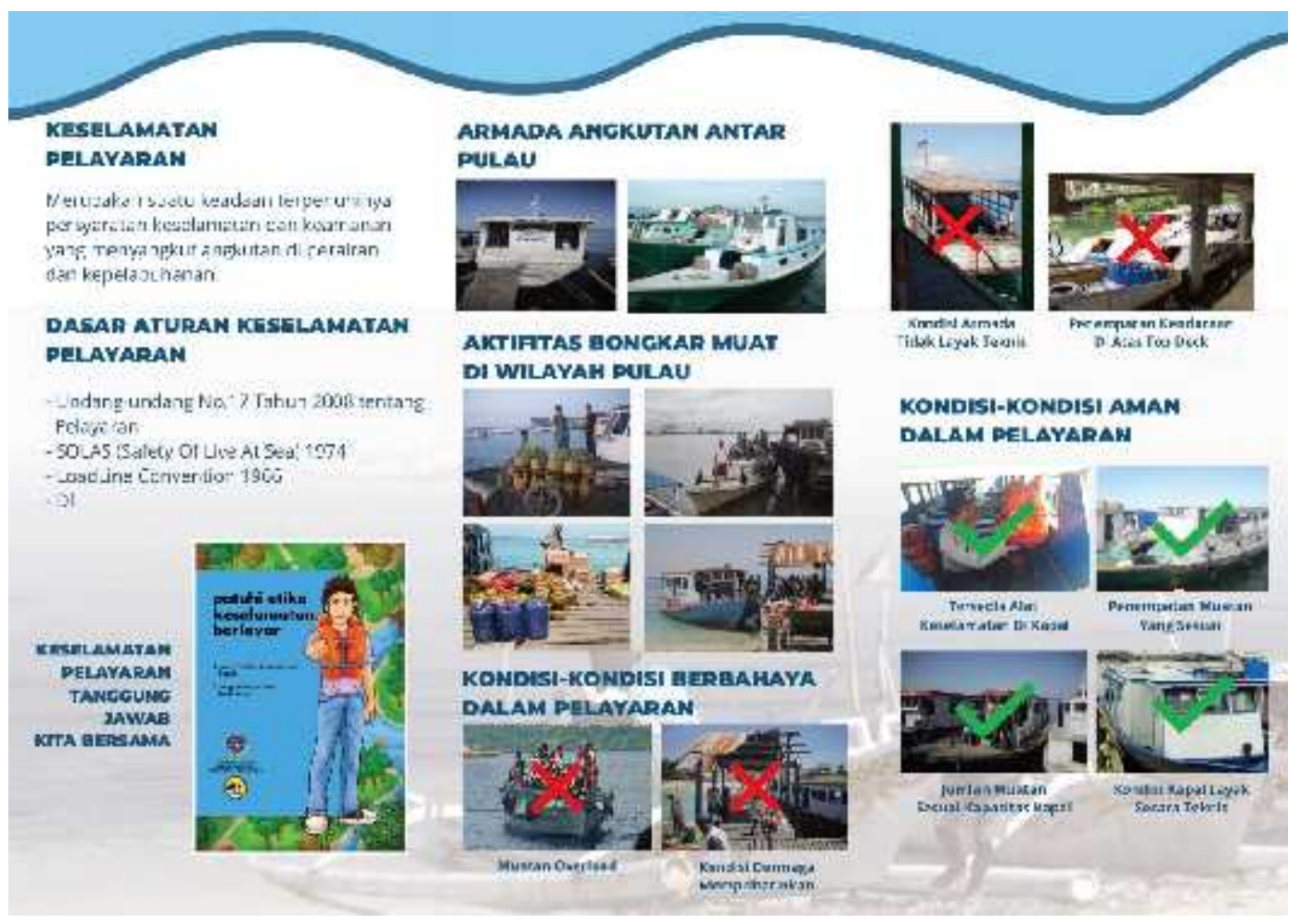

Gambar 3. Brosur/leaflet sosialisasi keselamatan pelayaran

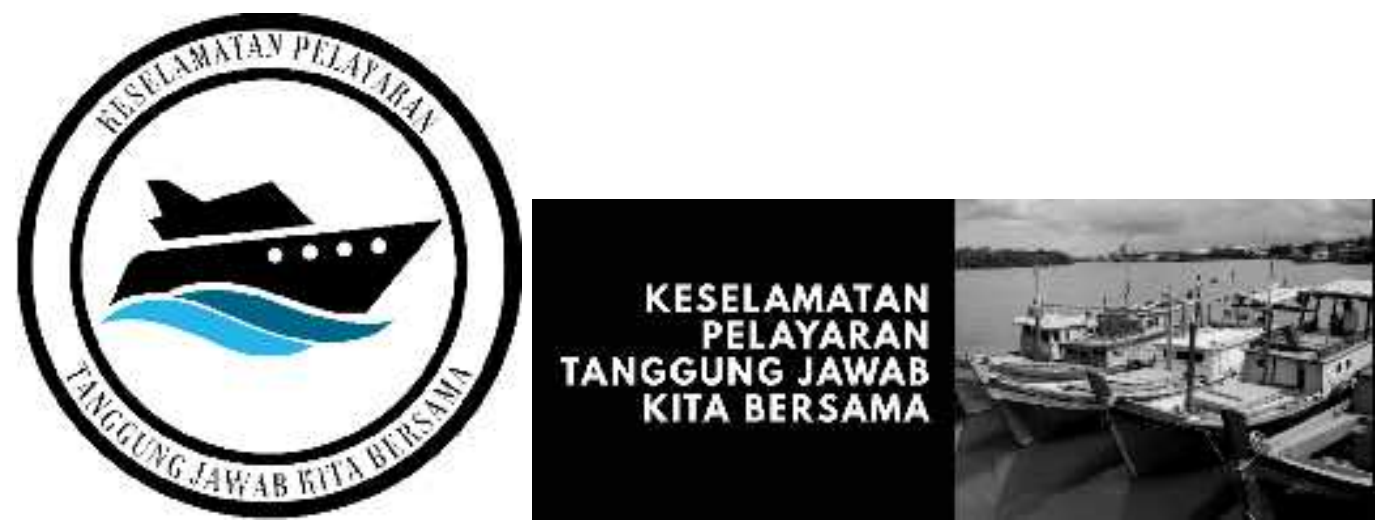

Gambar 4. Stiker sosialisasi keselamatan pelayaran

2. Tahap Pelaksanaan; tahapan ini meliputi pelaksanaan sosialisasi yang melibatkan tim kegiatan dan mahasiswa yang dilaksanakan di dua lokasi terminal angkutan pelayaran rakyat yang terdapat di Kota Makassar yaitu di Dermaga Kayu Bangkoa dan di Pelabuhan Paotere pada bulan Oktober 2020. Kegiatan sosialisasi dilakukan dengan memberikan pengarahan singkat dan membagi-bagikan brosur/leaflet keselamatan pelayaran serta stiker yang bertuliskan "keselamatan pelayaran tanggung jawab kita bersama" yang ditujukan kepada operator/pemilik armada dan pengguna jasa angkutan laut (Gambar 5, Gambar 6 dan Gambar 7). 

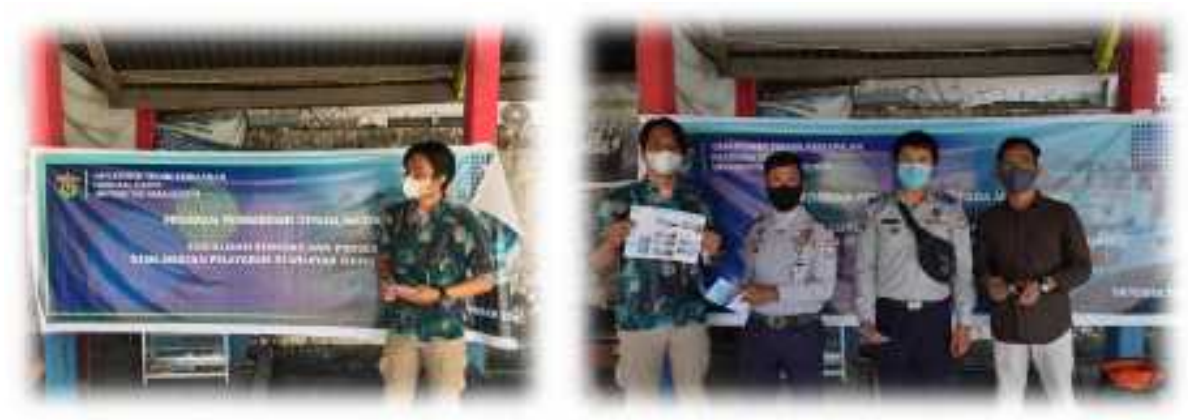

Gambar 5. Pengarahan singkat mengenai standar dan prosedur keselamatan pelayaran
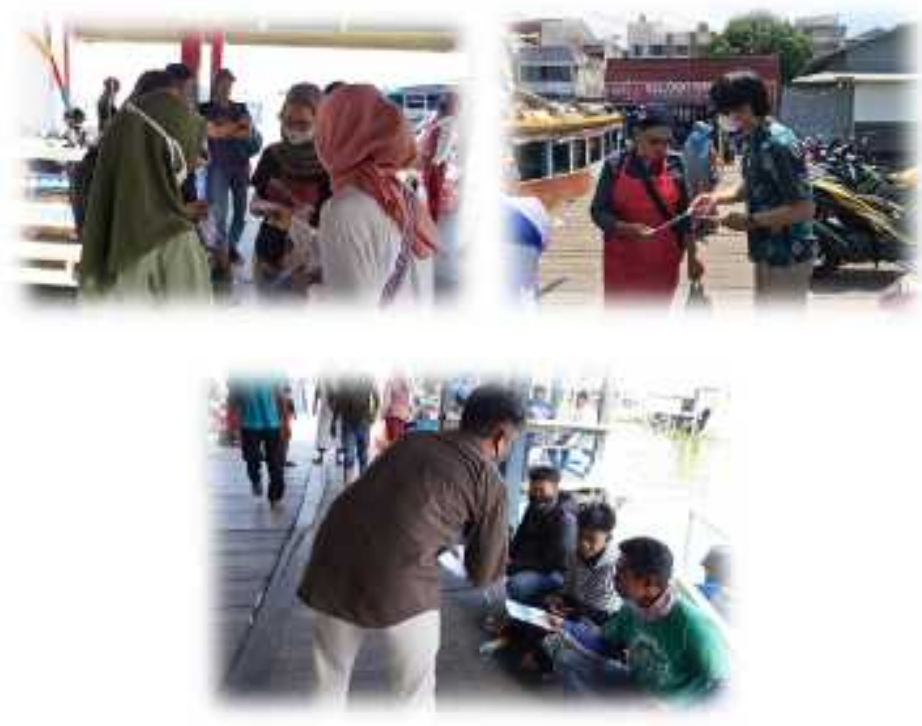

Gambar 6. Sosialisasi keselamatan pelayaran kepada operator dan pengguna jasa
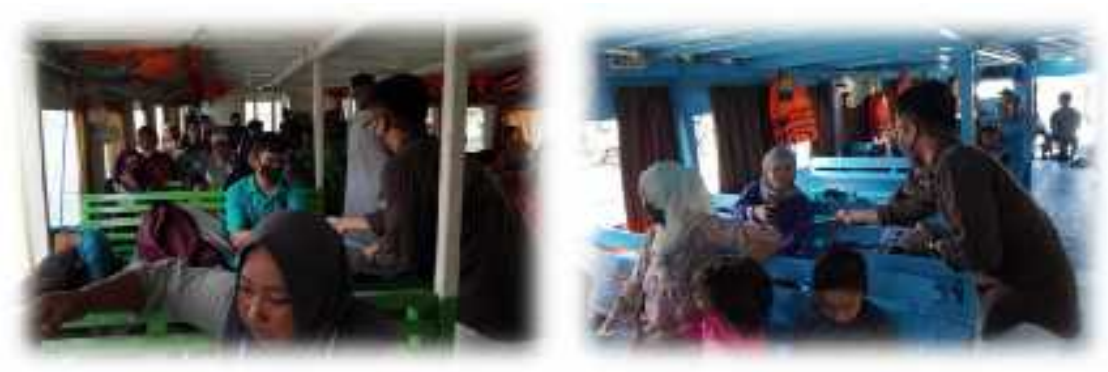

Gambar 7. Pembagian brosur dan stiker kepada pengguna jasa di atas kapal

\section{Hasil dan Diskusi}

Proses pelaksanaan kegiatan sosialisasi yang sedianya akan dilakukan dengan penyajian materi, namun karena kondisi di lokasi pengabdian tidak memungkinkan untuk pengumpulan massa yang disebabkan kondisi pandemic Covid-19 yang tidak mengizinkan untuk pengumpulan massa. Selain itu kesibukan pengguna jasa yang akan melakukan aktivitas di Kota Makassar tidak memungkinkan mereka untuk tetap berada di lokasi pengabdian karena kapal akan bertolak Kembali ke pulau pada pukul 11.00. 
Tingkat penyerapan materi sosialisasi dirasakan masih belum optimal sehingga perlu terus dilakukan sosialisasi keselamatan pelayaran kepada masyarakat pengguna jasa angkutan laut serta operator armada pelayaran rakyat yang melayani transportasi masyarakat wilayah kepulauan Sangkarrang.

\section{Kesimpulan}

Tingkat kesadaran operator dan pengguna jasa terhadap keselamatan pelayaran diharapkan semakin meningkat melalui sosialisasi yang telah dilakukan sehingga resiko kecelakaan dalam berlayar yang selama ini sering terjadi dapat berkurang khususnya pelayaran di wilayah gugus kepulauan Sangkarrang Kota Makassar. Selain itu pihak pemilik kapal diharapkan memperhatikan kondisi kapal dan kelengkapan alat-lat keselamatan standar yang harus tersedia di atas kapal.

\section{Ucapan Terima Kasih}

Ucapan terima kasih kami sampaikan kepada pihak-pihak pemilik kapal yang ada di Dermaga Kayu Bangkoa dan Pelabuhan Paotere serta pengguna jasa angkutan laut wilayah gugus Kepulauan Sangkarrang yang mau meluangkan waktu untuk mendengarkan pengarahan singkat dan sosialisasi dari tim kami. Terima kasih kepada Fakultas Teknik Universitas Hasanuddin yang telah memberikan Hibah Pengabdian Masyarakat sehingga kegiatan ini dapat terselenggara.

\section{Daftar Pustaka}

Peraturan Direktur Jenderal Perhubungan Laut, (2017). Persyaratan Kelaiklautan Kapal Tradisonal Pengangkut Penumpang. Nomor HK.103/2/8/DJPL-17, 18 April 2017.

Permen RI_A, (2015). Standar Keselamatan, Peraturan Menteri Perhubungan Republik Indonesia, No. 20.

Permen RI_B, (2015). Standar Pelayanan Penumpang Angkutan Laut, Peraturan Menteri Perhubungan Republik Indonesia, No. 37.

International Maritime Organization (IMO), (1999).

ISM (International Safety Management) Codes, (2002).

Keputusan Dirjen Perhubungan Laut Nomor, (1996). Sistem Manajemen Keselamatan. No. PY.67/1/9-96, 12 Juli 1996.

Ashury, (2020). Sosialisasi Keselamatan Pengguna Moda Transportasi Laut bagi Nelayan di Kabupaten Bone, Makassar. Jurnal TEPAT, Vol. 3 No. 1.

Keputusan Dirjen Perhubungan Laut Nomor, (2002). Keselamatan Pelayaran Rakyat. No. PY.66/1/2-02.

Peraturan Kepala Badan Diklat Perhubungan, (2010). Standar Pelatihan Dasar Keselamatan (BST) Khusus Awak Kapal dan Pekerja pada Kapal Layar Motor (KLM) dan kapal ikan dalam negeri. No. SK.225/DL-002/II/Diklat-2010. 